\title{
When online learning is a must: a case study of emergency remote teaching in higher education
}

Ingrid Noguera (corresponding author)

$\mathrm{PhD}$ in Multimedia Education. Serra Hunter Fellow at the Universitat Autònoma de Barcelona (Spain). Her research interests are teaching and learning in the digital society and innovative teaching methods. Latest publications cover e-assessment, mobilelearning and collaborative agile learning.

Paloma Valdivia

$\mathrm{PhD}$ in Education. Professor at the Universitat Autònoma de Barcelona (Spain). Her research is centered on the educational and social use of ICT, within the context of formal, non-formal and informal education. Her latest publications focus on Education and ICT for Development, Digital Social Innovation and Educational Programs' Sustainability.

\begin{abstract}
The health crisis caused by COVID-19 has urged face-to-face universities to adapt to the distance-teaching mode. This research seeks to analyse teaching and learning strategies and experiences during the confinement period in the context of the Faculty of Education of the Universitat Autònoma de Barcelona ( $\mathrm{N}=29$ teachers, 227 students). The results reveal that design of the course has reproduced face-to-face practices tending towards content-based learning. Lecturers have experienced difficulties deriving from a lack of digital competence and literacy in online pedagogies and students with reference to the paradigm shift that affect their role and tasks. In conclusion, there are pedagogical and technological changes that are here to stay and that the future of higher education will be hybrid. Teachers are predisposed to continue learning about the use of digital technologies and innovative teaching methods while there is a need to incorporate such competences into educators' educational programmes.
\end{abstract}

Keywords: distance education; emergency-remote teaching; teaching/learning perspective; digital competence; hybrid learning.

\section{Practitioner Notes}

What is already known about this topic:

- Universities were little prepared for an emergency.

- The COVID-19 pandemic is favouring the acceptation of technologies among teachers.

- There is a need to empower teachers to use digital technologies efficiently and to improve students' digital competences.

What this paper adds:

- Offers a dual perspective (teachers and students) on the application of emergency remote teaching.

- Provides specific proposals for technology-enhanced learning in intermittent faceto-face education.

- Opens up reflection about a new hybrid learning paradigm.

Implications for practice and/or policy: 
- New teaching modes are arising, such as ERT and intermittent face-to-face teaching, and their implications for education should be explored.

- New training needs of teachers have emerged and must be considered in educator's educational programmes.

\section{Introduction}

\section{The impact of the COVID-19 on face-to-face higher education}

Evidence shows that there is a need to empower teachers to use digital technologies efficiently in teaching-learning processes and to improve students' digital competences (Instefjord \& Munthe, 2015; Ramírez-Montoya, Mena, \& Rodríguez-Arroyo, 2017; Redecker, 2017; Reisoğlu \& Çebi, 2020). The literature demonstrates that the quality and efficiency of teaching improves when digital technologies and new forms of teacher training, learning and professional development are integrated (Amhag, Hellström, \& Stigmar, 2019). To this aim, there the European Framework for the Digital Competence of Educators (DigCompEdu) (Redecker, 2017) has been developed. Nevertheless, recent studies reveal that digital competence is still poorly integrated into teacher education programmes (Amhag, Hellström, \& Stigmar, 2019; Henderson, 2015; Insterjord, 2015).

The COVID-19 pandemic has forced universities to teach differently, obliging them to use and adapt to digital technologies in a very short period of time. Early investigations about the COVID-19 impact took shape as surveys were addressed to teachers and learners in order to gather preliminary information about the challenges and responses given to the situation (Lall \& Singh, 2020; Jegede, 2020) Results of an international research (Izumi, Sukhwani, Surjan \& Shaw, 2020) demonstrate that universities were little prepared for an emergency although participants consider the response to the emergency was timely and open. The challenges lie in the mode of teaching online lectures and working from home.

Qualitative investigations and theoretical reviews have offered insights about the strategies used and the lessons learned during the confinement period. La Velle, Newman, Montgomery and Hyatt (2020) propose teachers plan and teach well-structured lessons and make accurate and productive use of assessment. Bao (2020) suggests improving online student's support offering effective information, adequate teaching support, highquality participation and a technical contingency plan. Karalis (2020) offers several recommendations for educational emergencies, including the creation of a Crisis Management Team to implement and evaluate solutions.

The literature previously cited demonstrates that although digital technologies have been rapidly appropriated, there is a need to develop pedagogical and digital competences for the online context. What is clear is that the effects of the COVID-19 in higher education will, presumably, last longer than the pandemic and some of the changes applied will come to stay. Some teaching competences must be reviewed, emergency plans will be developed and the concept of face-to-face education itself will need to be reinterpreted.

\section{Emergency remote teaching}

The threat of COVID-19 has presented some unique challenges for HE institutions (Hodges, Moore, Lockee, Trust, \& Aaron Bond, 2020) which have had to close campuses suddenly and initiate online teaching (Bao, 2020). Education has become an emergency 
matter, and along with it, educational technologies have been positioned as a frontline emergency service (Williamson, Eynon, \& Potter, 2020). As a result, faculties have rushed to shift their curriculums to online environments (Crawford, Butler-Henderson, Rudolph, \& Glowatz, 2020) focusing on transitioning content and leaving aside reflection on online pedagogies (Crawford, 2020).

Such immediate transition to the online mode has been labelled as 'distance learning', 'remote teaching', and more specifically, 'emergency remote teaching (ERT)'. The authors of this paper have chosen the concept of ERT, understanding that the primary objective in these circumstances is not to re-create a robust educational ecosystem but rather to provide temporary access to instruction and instructional supports in a manner that is quick to set up and is reliably available during an emergency or crisis'(Hodges et al., 2020, p. 6). Currently, stakeholders are considering and making decisions about a new scenario called 'intermittent face-to-face teaching' (National Institute for Excellence in Teaching (NIET), 2020). This opens up a new understanding for managing a blended teaching model which is linked to the health crisis and involves periods of confinement or social distancing actions.

The results of this paper may contribute to dealing with future crises that may have an impact on face-to-face teaching. This research also invites reflection on the concept of physical presence and the distinction with virtuality. With an eye to recent events, will face-to-face education continue to be only physical? Is there a new paradigm of a hybrid education that use both environments depending on the teaching and learning needs? The pandemic is forcing HE to rethink the use of digital technologies and its teaching methods. This article provides some insights into a case of adaptation to ERT as well as describes the lessons learned and recommendations for future education.

\section{Purpose of this study}

The purpose of this study is to analyse the teaching and learning and experiences during the confinement period in the context of the Faculty of Education of the Universitat Autònoma de Barcelona (UAB) in order to extract the lessons learned in the event of a new crisis. The main objectives that have oriented the study are:

1. Explore the teachers' and student's perceptions in the design and application of ERT.

2. Make proposals and reflect on the use of digital technologies in face-to-face education within the new teaching-learning paradigm.

\section{Research method}

\section{Design}

This study has followed the multiple-case study method (Yin, 2018). Data collection lasted one and a half months and consisted of interviews with teachers and a survey for students. At the end of the Spring semester 2019-2020, a focus group was conducted to triangulate the data. Results were analysed qualitatively and quantitatively (survey). Based on evidence we have reached conclusions and make recommendations to academic staff for the design of courses where physical presence is temporary prohibited.

\section{Setting and participants}

The participants in this study were the academic staff of the Theories of Education and Social Pedagogy Department (TESP) of the Faculty of Education at the UAB (thirty-one 
teachers) and the undergraduate and Master's Degree students that were registered in the classes of these teachers during the confinement period (March-July). The teaching covered four Bachelor's degrees and three Master's degrees. It included 26 mandatory and optional courses (some of them were given in several degrees) and tutoring the Bachelor's Degree Final Project (BDFP) and the Master's Degree Dissertation (MDD). Eight hundred and sixty-six students were registered in the Bachelor's Degree courses and 120 in the Master's Degree courses. The total sample obtained in the survey for the Bachelor's Degrees consisted of 218 students and 9 for the Master's Degree, $97 \%$ of them were between 18 and 30 years old. The response ratio was $30.08 \%$ for undergraduate students and $8.62 \%$ for Master's students. Twenty-nine teachers participated $(93.54 \%$ of the total sample) in the interviews.

The Moodle platform was used as the LMS and Microsoft Teams as the communication tool.

\section{Research instruments and data collection}

First, a documentary analysis (teaching plans of the department and literature review) was carried out to develop the theoretical framework and to construct the survey. Second, an observation was conducted during an online plenary meeting at the department (about 20 participants) at the end of March that served for developing the interview instrument. Third, the teachers' perspective was collected through a semi-structured interview consisting of 6 items regarding their experience in designing and implementing distance learning. All interviews were conducted on line between 1st April and 1st May of 2020. Interviewed teachers were anonymous with an identifier given to each one (Ix). Four, a student survey was passed on line between May 13th and May $28^{\text {th }}$ to those students registered in the classes of the teachers that were giving them during the Spring semester of 2020. The aim was to find out about their learning experience in a distance context. The students completed the surveys anonymously. The survey consisted of 21 items including closed-answer items, open-answer items, multiple-choice items and Likert scale items (labelled from ' 1 strongly disagree' to ' 5 strongly agree'). This instrument has been used to respond to the first and third objectives. Finally, in mid-July, an online focus group was conducted through Microsoft Teams with the academic staff of the department (seven teachers) to triangulate data. Participants were anonymous with an identifier given to each one (Px). Considering the small ratio of participants, the data obtained from this instrument is used to emphasize or oppose to results from teachers' interviews and students' survey.

\section{Data analysis}

The interviews, the focus group and the open-answer items of the survey were analysed qualitatively using the Atlas.ti software. A thematic analysis was conducted to code and process the interviews. Regarding the focus group, citations were coded according to the first two research objectives: teachers' and students' perspectives and learning scenarios. As regards the survey, responses were analysed using SPSS software. Data from items not based on Likert scales are presented as a percentage. A descriptive analysis was conducted for those items based on Likert scales (6,8 and 10). Data from these items are presented based on the mean and standard deviation.

The results obtained through the responses to the survey are not sufficient to generalise and could not be representative of the entire population. Nevertheless, we consider that they throw light on the feelings of students and are useful when compared with the views 
of teachers. The findings presented below seek to describe the specific case of the teachers and students of the TEPD department who participated in the study.

\section{Results}

The results are presented considering the first two objectives of the study.

\section{Teachers' and students' perceptions}

I. Teachers' perspective

In terms of teaching strategies, the most common actions undertaken refer to the creation of information resources (generating instructions or reducing information from the course materials), flexibility (time, submissions and grouping) and teaching coordination. Other comments mention the reduction of requirements or connecting the topic of the course with the reality of confinement:

The difficulties that teachers have most experienced are related to work overload, technological problems (with videoconferencing tools and the Moodle platform), and the anxiety caused by the sudden transition to virtual teaching (absence of online teaching knowledge and the lack of digital skills). Most comments refer to synchronous communication difficulties and the rise of e-mails and tutoring. To a lesser extent, other aspects mentioned are improvisation, uncertainty, difficulties to identify students using Microsoft Teams, students' lack of self-management skills and non-existence of indications from coordination teams:

Regarding the solutions that have been sought to deal with the problems, in relation to teaching needs, the most common has been to explore various tools to find the one that best respond to the pedagogical requirements and support between workmates. Some participants affirm they have undertaken training in tools and strategies and have also asked for help from colleagues and relatives. As for the actions aimed at improving the students' experience, teachers have used the chat tool to encourage student participation in videoconferencing sessions and have offered resources in different formats. Other solutions include providing more support to students, forcing students to participate or offering written material.

One of the great opportunities that most teachers mention (in the interviews and focus group) is the new learning that the situation has allowed to develop with reference to the use of digital technologies (particularly videoconferencing tools). There is also a certain quorum considering that the situation has favoured flexibility (as both teachers and students were at home and could be more open to changes) and systematisation (as the distance mode required more structure and order). Some teachers have experienced distance teaching as an opportunity to get to know more the students, rethink the courses or increase class attendance and participation. Concerning future improvements, participants raise strategies related to reviewing the format of contents, offering more instructions, conducting videoconferencing sessions, or delimiting the use of communication channels.

Even in the case of teachers with lower digital skills or with little interest in technology, there is a predisposition to continue using the technologies once they return to face-toface teaching. As participants expressed, 'it is not as limiting as I thought' (I16) and 'it must be complementary' (I15). In general, despite the initial reluctance and fears teachers 
have experienced less difficulties than expected and consider some changes will last beyond the pandemic.

\section{Students' perspective}

Concerning the demographic data, the majority of students (97\%) are in the 18-30 age group and study full time (80\%). A large proportion of students consider themselves as intermediate technology users (high-intermediate 56\%, low-intermediate 24\%). Most of the students who answered the survey came from the degrees in Pedagogy (29\%), followed by Early Childhood Education (21.6\%), Primary Education (19.8\%) and Social Education (19.8\%). These differ in the sample obtained for the double degree in Early Childhood and Primary Education and the Master's degree.

In terms of equipment and connectivity, $59 \%$ of students report having used the laptop to follow the classes ( $40 \%$ used a mobile phone, $13 \%$ a desktop computer and $10 \%$ a tablet) and $92 \%$ of them used a Wi-Fi connection. $57 \%$ affirm they have experienced connectivity issues, $74 \%$ declare having a suitable physical environment to follow the classes and $60 \%$ do not share the computer with others. The intensive use of videoconferences connected through WIFI may explain the connectivity issues.

In item 6, 'Which aspects of distance learning have been particularly difficult', the majority of students declare they experienced mostly all the difficulties presented. The mean for all statements (hereafter ' $\mathrm{s}$ ') is higher than 3.6 points, which indicates students consider having experienced numerous difficulties during distance learning, particularly with reference to the lack of physical presence (s11) and communication (s12). Indeed, in the end, they affirm that they prefer face-to-face courses (s10). The only statement valued under 3 is digital competences (s8) which do not appear to be a disadvantage. The SD for all items is under 0.3 (except for item 8 which is 0.5 ) indicating that responses are fairly homogeneous.

Regarding the obstacles experienced by students, during the focus group, teachers speculated about the reasons students may have sustained their complaints. These include the world crisis context, the situation of uncertainty and the lack of pedagogical adaptation to the virtual context.

As for item 8, 'Which aspects of learning at a distance have been particularly beneficial?', the mean for the majority of statements is ranged under 3 points (e.g. self-paced learning, learning control, feeling supported by the teacher) which reveals students have found few opportunities with this mode of learning. The statements about the possibility to continue learning (s1), interaction with classmates (s6) and saving time in commuting (s2) obtained the highest rates which indicate those elements have been the most beneficial in their opinion. The SD is under 0.4 in all cases which shows a homogeneous response in all items. Regarding the open answers for item 8, students emphasise the concern and empathy of some teachers, videoconferencing sessions, having more time, not having an attendance list, the recording of lectures and receiving information on the situation at the educational level.

Of these solutions, 'Which teaching strategies have been particularly useful?', the best rated are those referring to tutoring through videoconference (s10), lecture via videoconference $(\mathrm{s} 3)$ and lessons through video recordings (s1). On the contrary, forum 
discussions (s8), PowerPoint resources (s2) and written material (s7) are the worst-rated. The majority of statements are ranged under three, which indicates students, in general, find the strategies implemented by teachers of little use. The SD is under 0.4 which demonstrates a high homogeneity on students' responses for all items. In the open response item, participants consider strategies of co-evaluation, feedback of projects, and the use of Padlet or Drive to share content as useful.

\section{Discussion, lessons learned and proposal}

The first lesson learned is that the intensive appropriation of technologies experienced has modified the teachers' perspective on their utility and is making it necessary to rethink teaching. Perhaps the advances achieved during the pandemic will be a catalyst for the necessary development of digital competence among teachers. This, in turn, could impact positively on developing digital teaching competence among Education students. Although the students participating in this research consider they master the use of digital technologies, it does not mean they are competent in their effective use for teaching purposes.

The second lesson learned is that using the time with large groups for giving lectures no longer makes sense. The majority of teachers have expressed their intention to flip their classrooms using technologies to promote the autonomous development of knowledge through resources and activities, and profiting the synchronous face-to-face sessions for active learning and communication.

The third lesson learned is that new knowledge is needed to teach on line, or in blended mode, as the strategies and knowledge teachers have are not sufficient for such a new context. On the one hand, teachers felt overcome by the ethical aspects of teaching on line. On the other hand, according to Crawford (2020), there is a need to continuoulsy monitor the quality of the learning design. In the case of the teachers and students participating in this study, there is a sustained concern about the quality of online teaching. There is a practical part based on group dynamics and the loss of immediate feedback that teachers have not been able to transform quickly into a digital context and that students have missed.

The fourth lesson learned is that students still prefer replicating traditional modes of teaching, whether they use technologies or not. They appreciate content-based learning in an audio-visual format supported by teaching explanations and the individualisation of learning.

\section{Conclusions, limitations and future research}

This study attempted to propose an approach for adapting face-to-face courses to intermittent physical attendance. The results obtained from students' surveys and teacher's interviews and the focus group reveal that the sudden transition to the online delivery mode only permitted transferring the content digitally and offered little time for rethinking teaching and learning. Nevertheless, the students' opinions and teachers' reflections offer exciting ideas for designing courses and adapting to a new crisis.

First, there is a need to continue training teachers in digital competences as well as innovative teaching methods. There is a unique opportunity for institutions to train their 
teachers as they are currently disposed and convinced of the benefits of technologies and the need for a shift in teaching methods. Second, the redesign of courses must be done breaking with the distinction between face-to-face and online learning. Undoubtably, the present and the future will be hybrid. Face-to-face universities must design their courses profiting from the benefits of the two worlds and ensuring that new designs will resist intermittent and interchangeable delivery modes derived from future crises. Third, the world has changed forever, and education must do also. Even those education students who are reluctant to use innovative teaching methods and technologies will need to be more competent in digital technologies for teaching and creative problem-solving. Teachers have been forced to develop such competences rapidly. Future educators need to have these competences transversally and continuously incorporated in their education programme.

From the research point of view, further investigation should be conducted with a larger sample of students and teachers from diverse disciplines as the participants of this study are a very specific target. Other disciplines may show different results and reach different conclusions. The major implications of this study for researchers are, first, to reconsider the distinction between face-to-face and distance learning and investigate the teaching modes that are arising such as ERT and intermittent face-to-face teaching and their implications for education. Second, to embark on a new line of research into the new training needs of teachers. The constraints and contexts we have known have been dramatically changed and a new uncertain future is to come. We need to be prepared from the academic and research world to cope with the new and immediate demands society will demand of us.

\section{Acknowledgments}

The authors would like to express their gratitude to all the teachers and students who participated selflessly in this study. We would like to thank Professor Josefina Sala and Carla Quesada for their support in the development and review of this study.

\section{Statements on open data, ethics and conflict of interest}

The data consist of personal perspectives of students and teachers regarding teaching and learning. We have not asked for consent to share the data.

Data was anonymised, participants freely consented to participate and were informed about the purpose of the research. Collection, analysis and storage of data followed the institutional's guidelines for data protection.

There is no conflict of interest.

\section{References}

Albó, L., Beardsley, M., Martínez-Moreno, J., Santos, P., \& Hernández-Leo, D. (2020). Emergency Remote Teaching: Capturing Teacher Experiences in Spain with SELFIE. In C. Alario-Hoyos, Rodríguez-Triana; María Jesús, M. Scheffel, I. Arnedillo-Sánchez, \& S. M. Dennerlein (Eds.), Addressing Global Challenges and Quality Education (pp. 318-331). Heidelberg: Springer Nature Switzerland. https://doi.org/10.1007/978-3-030-57717-9_23

Almerich, G., Orellana, N., Suárez-Rodríguez, J., \& Díaz-García, I. (2016). Teachers' information and communication technology competences: A structural approach. $\begin{array}{llll}\text { Computers } \& \text { Education, } & 1100-125 .\end{array}$ https://doi.org/10.1016/j.compedu.2016.05.002

Amhag, L., Hellström, L., \& Stigmar, M. (2019). Teacher Educators' Use of Digital Tools 
and Needs for Digital Competence in Higher Education. Journal of Digital Learning in Teacher Education, 35(4), 203-220. https://doi.org/10.1080/21532974.2019.1646169

Azorín, C. (2020). Beyond COVID-19 supernova. Is another education coming? Journal of Professional Capital and Community. Emerald Group Publishing Ltd. https://doi.org/10.1108/JPCC-05-2020-0019

Bao, W. (2020). COVID-19 and online teaching in higher education: A case study of Peking University. Human Behavior and Emerging Technologies, 2(2), 113-115. https://doi.org/10.1002/hbe2.191

Crawford, J. (2020). COVID-19: 20 countries' higher education intra-period digital pedagogy responses. Journal of Applied Learning \& Teaching, 3(1), 09-28. https://doi.org/10.37074/jalt.2020.3.1.7

Faderogaya, S. L., \& Chantagul, N. (2019). Learning styles and attitude towards elearning among university undergraduate students in international programs in Bangkok Thailand. Scholar: Human Sciences, 11(1), 118-122. Retrieved from http://repository.au.edu/handle/6623004553/22338

Felea, M., Albastroiu, I., Vasiliu, C., \& Georgescu, B. (2018). e-Learning in Higher Education: Exploratory Survey among Romanian Students. In The 14th International Scientific Conference eLearning and Software for Education (pp. 157162). Bucharest: Advanced Distributed Learning Association. https://doi.org/10.12753/2066-026X-18-237

García, L. (2017). Educación a distancia y virtual: calidad, disrupción, aprendizajes adaptativo y móvil. RIED. Revista Iberoamericana de Educación a Distancia, 20(2), 09-25. https://doi.org/10.5944/ried.20.2.18737

García, L. (2019). El problema del abandono en estudios a distancia. Respuestas desde el Diálogo Didáctico Mediado. RIED. Revista Iberoamericana de Educación a Distancia, 22(1), 245-270. https://doi.org/10.5944/ried.22.1.22433

Henderson, M., Selwyn, N., \& Aston, R. (2015). What works and why? Student perceptions of 'useful' digital technology in university teaching and learning. Studies in Higher Education, 42(8), 1567-1579. https://doi.org/10.1080/03075079.2015.1007946

Hodges, C., Moore, S., Lockee, B., Trust, T., \& Aaron Bond. (2020). The Difference Between Emergency Remote Teaching and Online Learning | EDUCAUSE. Retrieved 6 August 2020, from https://er.educause.edu/articles/2020/3/thedifference-between-emergency-remote-teaching-and-online-learning

Instefjord, E., \& Munthe, E. (2015). Preparing pre-service teachers to integrate technology: an analysis of the emphasis on digital competence in teacher education curricula. European Journal of Teacher Education, 39(1), 77-93. https://doi.org/10.1080/02619768.2015.1100602

Izumi, T., Sukhwani, V., Surjan, A., \& Shaw, R. (2020). Managing and responding to pandemics in higher educational institutions: initial learning from COVID-19. International Journal of Disaster Resilience in the Built Environment, (ahead-ofprint). https://doi.org/10.1108/IJDRBE-06-2020-0054

Jegede, D. (2020). Perception of Undergraduate Students on the Impact of COVID-19 Pandemic on Higher Institutions Development in Federal Capital Territory Abuja, Nigeria. Electronic Research Journal of Social Sciences and Humanities, 2(11), 211-222. Retrieved from www.eresearchjournal.com

Karalis, T. (2020). Planning and evaluation during educational disruption: Lessons learned from Covid-19 pandemic for treatment of emergencies in education. European Journal of Education Studies, 7(4), 2020. 
https://doi.org/10.5281/zenodo.3789022

Kattoua, T., Al-Lozi, M., \& Alrowwad, A. (2016). A Review of Literature on E-Learning Systems in Higher Education. International Journal of Business Management and Economic Research(IJBMER), 7(5), 754-762. Retrieved from www.ijbmer.com

King, L., Jorgensen, M., Lussier, A., Fichten, C., Havel, A., Amsel, R., ... Cegep AndreLaurendeau (Canada). (2017). Student and Professor Perspectives on Exemplary Practices in the Use of Information and Communication Technologies (ICTs) and E-Learning in Colleges. Canada. Retrieved from https://eric.ed.gov/?id=ED574860

la Velle, L., Newman, S., Montgomery, C., \& Hyatt, D. (2020). Initial teacher education in England and the Covid-19 pandemic: challenges and opportunities. Journal of Education for Teaching, 1-13. https://doi.org/10.1080/02607476.2020.1803051

Lall, S., \& Singh, N. (2020). COVID-19: Unmasking the new face of education. International Journal of Research in Pharmaceutical Sciences, 11(Special Issue 1), 48-53. https://doi.org/10.26452/ijrps.v11iSPL1.2122

Martin, F., Sun, T., \& Westine, C. (2020). A systematic review of research on online teaching and learning from 2009 to 2018. Computers \& Education, 159, 104009. https://doi.org/10.1016/j.compedu.2020.104009

Ministerio de Universidades. (2020). Datos y Cifras del Sistema Universitario Español (Publicación 2019-2020). Madrid. Retrieved from https://www.ciencia.gob.es/portal/site/MICINN/menuitem.26172fcf4eb029fa6ec7d a6901432ea0/?vgnextoid=364e006e96052710VgnVCM1000001d04140aRCRD

Murphy, M. P. A. (2020). COVID-19 and emergency eLearning: Consequences of the securitization of higher education for post-pandemic pedagogy. Contemporary Security Policy, 41(3), 492-505. https://doi.org/10.1080/13523260.2020.1761749

National Institute for Excellence in Teaching (NIET). (2020). Planning \& Support guide scenarios and considerations for 2020-21. Nashville. Retrieved from https://www.niet.org/our-work/brochures/category/2020-21-school-year-planning

Quezada, R. L., Talbot, C., \& Quezada-Parker, K. B. (2020). From bricks and mortar to remote teaching: a teacher education programme's response to COVID-19. Journal of Education for Teaching, 1-12. https://doi.org/10.1080/02607476.2020.1801330

Ramírez-Montoya, M. S., Mena, J., \& Rodríguez-Arroyo, J. A. (2017). In-service teachers' self-perceptions of digital competence and OER use as determined by a xMOOC training course. Computers in Human Behavior, 77, 356-364. https://doi.org/10.1016/j.chb.2017.09.010

Redecker, C. (2017). European framework for the digital competence of educators: DigCompEdu. Joint Research Centre (JRC) Science for Policy report. https://doi.org/10.2760/159770

Reisoğlu, İ., \& Çebi, A. (2020). How can the digital competences of pre-service teachers be developed? Examining a case study through the lens of DigComp and DigCompEdu. Computers and Education, 156, 103940. https://doi.org/10.1016/j.compedu.2020.103940

Scull, J., Phillips, M., Sharma, U., \& Garnier, K. (2020). Innovations in teacher education at the time of COVID19: an Australian perspective. Journal of Education for Teaching, 1-10. https://doi.org/10.1080/02607476.2020.1802701

Williamson, B., Eynon, R., \& Potter, J. (2020, April 2). Pandemic politics, pedagogies and practices: digital technologies and distance education during the coronavirus emergency. Learning, Media and Technology. Routledge. https://doi.org/10.1080/17439884.2020.1761641

Yin, R. (2018). Case Study Research and Applications: Design and Methods. (Sage publications, Ed.) (Sixth Edit). California: SAGE Publications Ltd. Retrieved from 
https://us.sagepub.com/en-us/nam/case-study-research-andapplications/book 250150 